\title{
Irradiation effects in oxide glasses doped with transition and rare-earth
}

\section{elements}

\section{E Malchukova ${ }^{1}$, B Boizot ${ }^{1}$, G Petite $^{1}$ and D Ghaleb ${ }^{2}$}

${ }^{\mathrm{a} C E A}$ /DSM/DRECAM, Laboratoire des Solides Irradiés, UMR 7642, CNRS-CEA-Ecole

Polytechnique, Ecole Polytechnique, 91128 Palaiseau Cedex, France.

${ }^{\mathrm{b}} \mathrm{CEA} / \mathrm{DEN} / \mathrm{DTCD} / \mathrm{SECM}$, Laboratoire d'études du Comportement à Long Terme, CEA

Valrho-Marcoule, BP 171, 30207 Bagnols-sur-Cèze Cedex, France.

e-mail: genia@poly.polytechnique.fr

\begin{abstract}
The effect of $\beta$-irradiation on silicate and aluminoborosilicate glasses doped with transition metals (TM) and rare earth (RE) elements has been studied using Electron Paramagnetic Resonance (EPR), Raman and luminescence spectroscopy. Irradiation leads to the reduction of both $\mathrm{Cr}$ and $\mathrm{Mn}$ ions in both types of glass matrix. It is shown that even small amounts of TM dopants completely block defect production, as occurs under irradiation in non-doped glasses. As well, TM doping results in the disappearance of structural changes in the glass (densification, polymerization increase and Na migration) for doses of $\sim 10^{9} \mathrm{~Gy}$. Unlike TMdoped matrices, incorporation of RE ions into aluminoborosilicate glass blocks neither defect production nor structural changes in glass matrices during irradiation. Simultaneously, we observe a reduction of $\mathrm{RE}$ ions, most clearly demonstrated for $\mathrm{Ce}^{4+}$ ions in aluminoborosilicate glasses. We propose that the relative stability of the different charge states of the RE ions is linked to the efficiency of the reduction process, and therefore to the evolution of the glass structure during irradiation.
\end{abstract}

keywords : transition and rare earth ions, glasses, $\beta$-irradiation, EPR, Raman, reduction 


\section{Introduction}

The confinement of high-level nuclear waste (HLW) into borosilicate glass is an internationally accepted technology for the immobilization of this radioactive material [1-3]. For use in the immobilization of nuclear waste, borosilicate glasses must be durable over the thousands of years that the waste will remain hazardous. Therefore, prediction of the longterm behaviour and stability of these glasses is of great importance. It is known that structural evolution of the nuclear glass due to self-irradiation during such long-term storage can modify its confinement properties [4]. To study of the consequences of $\beta$ decay, the effect of $\beta$ irradiation on the structure of simplified borosilicate glasses has been investigated [5-6].

We have shown in previous studies that simplified nuclear waste glasses suffer significant structural changes under $\beta$-irradiation [5-6]. An increase of glass polymerization and the formation of dissolved molecular oxygen have been shown by Raman spectroscopy [5] and several paramagnetic defects have been identified by electron paramagnetic resonance (EPR) spectroscopy [6]. The paramagnetic defects that have been identified are the following: (i) the silicon peroxy radicals $\left(\equiv \mathrm{Si}-\mathrm{O}-\mathrm{O}^{\bullet}\right)[7]$, (ii) the $\mathrm{E}^{\prime}$ center $\left(\equiv \mathrm{Si}^{-}\right)[8]$, (iii) the $\mathrm{HC}_{1}$ center $(\equiv \mathrm{Si}-$ $\left.\mathrm{O}^{\bullet} \mathrm{Na}^{+}\right)[9-10]$, and (iv) the boron oxygen hole center $(\mathrm{BOHC})\left(\equiv \mathrm{Br}-\mathrm{O}^{\bullet}\right)[11]$. As well, it has been shown that structural modifications in irradiated nuclear simplified glasses can be attributed to the migration of network modifier ions, such as sodium [12-14]. A decrease in the motion of the alkaline atoms results in less prominent structural changes, and may be the reason for a decrease in the number of paramagnetic defects [15]. Additionally, a restriction or annihilation of defects (mainly, the BOHC) can be obtained by doping the glass with Gd(Sm) or Fe ions [16-18]. This phenomenon can be explained by the greater probability of charge trapping between the two charge states of the doping ion (redox couples $\mathrm{Fe}^{3+} / \mathrm{Fe}^{2+}$ and/or $\mathrm{Sm}^{3+} / \mathrm{Sm}^{2+}$ ) in comparison with the breaking of Si-O-Si bonds [16-18]. 
It is desirable that the transition or rare earth elements be immobilized (vitrified) in the glass matrix as toxic ions and/or fission products of self-irradiation decay [19-20]. Consequently, the structural changes that occur in real nuclear glasses can be simulated by the introduction of TM and/or RE atoms into the glass network; this technique can be used to determine the evolution in the TM and RE ion environments, as well as any structural modifications in the glass matrix that they may cause [20-24]. While TM's may themselves be toxic [20], RE elements are not radioactive, and can therefore be easily handled and used as simulants for actinides (because of their very similar physical and chemical properties) [21-24]. For instance, neodymium may be used as a surrogate for the trivalent minor actinides: americium and curium. Cerium - which exhibits both " $+3 "$ and " $+4 "$ oxidation states - is used as a surrogate for uranium and plutonium when both oxidation states need to be considered [21].

The aim of this work is the systematic study of structural evolution in TM- and RE-doped oxide glasses when exposed to $\beta$-irradiation. Electron paramagnetic resonance (EPR), Raman scattering, and photoluminescence measurements were performed in order to reveal the influence of the TR or RE reduction mechanisms on their environments in silicate and aluminoborosilicate glasses. In addition, these measurements were used to investigate the structural changes in the glass caused by the embedding of TM and RE ions, including any dependence on dopant concentration.

\section{Experimental}

For this study, two series of oxide glasses were analyzed. The first series was composed of silicate glass prepared by mixing stoichiometric amounts of $\mathrm{SiO}_{2}$ and $\mathrm{Na}_{2} \mathrm{CO}_{3} \cdot \mathrm{Cr}_{2} \mathrm{O}_{3}$ was then added to the mixture to obtain different chromium-doped silicate glasses from 0.07 to $0.69 \mathrm{~mol} \%$. The second series consisted of aluminoborosilicate glasses, prepared by mixing stoichiometric amounts of $\mathrm{SiO}_{2}, \mathrm{Al}_{2} \mathrm{O}_{3}, \mathrm{H}_{3} \mathrm{BO}_{3}, \mathrm{Na}_{2} \mathrm{CO}_{3}$, and $\mathrm{ZrO}_{2}$, and then doped with 
different amounts of RE or manganese oxide. This resulted in doping concentrations from 0.17 to 0.83 , or from 0.12 to $1.71 \mathrm{~mol} \%$, respectively. The dried mixed powders were first heated at $750{ }^{\circ} \mathrm{C}$ in a $\mathrm{Pt}$ crucible during 10 hours for decarbonation. They were then melted at $1500{ }^{\circ} \mathrm{C}$ for one hour before being quenched in air. The glasses were annealed at $500{ }^{\circ} \mathrm{C}$ during a few hours to relieve any strain. Each glass was analyzed by X-Ray diffraction to confirm its amorphous character.

All samples were irradiated using $2.5 \mathrm{MeV}$ electrons generated by a Van de Graaf accelerator. The sample temperature during irradiation was kept near $50^{\circ} \mathrm{C}$ by water cooling the sample holder. A glass thickness of about $0.5 \mathrm{~mm}$ was used in order to obtain homogeneous irradiation over the glass volume. A $4.10^{9}$ Gy dose of irradiation via a $14 \mu \mathrm{A}$ beam was used for each sample. EPR spectra were obtained using an $X$ band $(v \approx 9.420 \mathrm{GHz})$ EMX Bruker spectrometer at room temperature with $100 \mathrm{kHz}$ field modulation and $3 \mathrm{G}$ amplitude modulation. Different microwave power levels (1 $\mathrm{mW}$ and $20 \mathrm{~mW})$ were used to study of EPR signal of the defects (in order to avoid defect saturation), as well as the EPR lines belonging to $\mathrm{Cr}$ or $\mathrm{Mn}$ ions. All EPR spectra have been normalized to a sample weight of $100 \mathrm{mg}$. Error estimation for all the data obtained has taken into account contributions from both random and systematic errors. All uncertainties have thus been considered and are displayed in the figures. After irradiation, luminescence and Raman spectra were collected on a Labram HR micro-spectrometer using the $514.5 \mathrm{~nm}$ line of an $\mathrm{Ar}^{+}$laser. These measurements were carried out using a x50 Olympus objective and an incident laser power of about $20 \mathrm{~mW}$ to avoid significant heating of the samples.

\section{Results}

\subsection{Structural evolution of Cr-doped glasses}


Fig. 1 presents the evolution of the Raman spectra of the silicate glasses with increasing chromium concentration. One can notice a small shift towards lower frequencies for the broad Raman peak at $\sim 480 \mathrm{~cm}^{-1}$ attributed to Si-O-Si bending vibration modes. No significant changes are observed in Cr-doped glasses in comparison with the un-doped silicate glasses, except for the appearance of new bands at 845 and $900 \mathrm{~cm}^{-1}$ that appear even at low chromium concentration $(0.13 \mathrm{~mol} \%)$. The intensity of the bands increases with chromium concentration and becomes very pronounced for the highest $\mathrm{Cr}$ contents $(0.69$ and $1.08 \mathrm{~mol}$ \%). These bands are attributed to the vibration modes of crystallized chromium oxides [2526]. It is seen (Fig.1) that the proportion of the crystalline phase in these glasses is small, and that the majority of the chromium is dissolved in the amorphous matrix.

The Raman spectra of the five aluminoborosilicate glasses doped with different contents of chromium are presented in Fig. 2. As was found for silicate glasses, the addition of chromium did not have a significant influence on the structure. On the other hand, the bands at 350, 850 and $900 \mathrm{~cm}^{-1}$ in these spectra appear to be correlated with crystallized chromium oxides [26]. For the highest chromium concentration $(1.04 \mathrm{~mol} \%)$ the fine structure of the line at $900 \mathrm{~cm}^{-1}$ can be discerned (inset of Fig. 2).

Figure 3 shows the Raman spectra of pristine and irradiated (1.6 .10 Gy) silicate glasses doped with different chromium concentrations. All spectra were normalized to the intensity of the band at $\sim 480 \mathrm{~cm}^{-1}[27]$. During irradiation at 1.6.109 Gy for the un-doped silicate glass samples, the Si-O-Si bond bending vibrations band $\left(480 \mathrm{~cm}^{-1}\right)$ shift to higher frequency, indicating a decrease of the average $\mathrm{Si}-\mathrm{O}-\mathrm{Si}$ angle. However, the shift is considerably reduced with increasing chromium content in the glass (Fig.3). The sharp bands at $490\left(\mathrm{D}_{1}\right)$ and 602 $\mathrm{cm}^{-1}\left(\mathrm{D}_{2}\right)$ correspond to the symmetric oxygen breathing vibrations of four- and threemembered siloxane rings, respectively [28-29]. Signals in the $900-1200 \mathrm{~cm}^{-1}$ frequency region are classically assigned to the Si-O symmetric bond stretching modes of the so-called $\mathrm{Q}^{\mathrm{n}}$ 
species (i.e. $\mathrm{SiO}_{4}$ units with $n$ bridging oxygens) [27]. In the Raman spectrum of pristine undoped silicate glass, bands at about 1090 and $1150 \mathrm{~cm}^{-1}$ are associated with $\mathrm{Q}^{2}$ and $\mathrm{Q}^{3}$ species, respectively. A sharp, weak band at $1550 \mathrm{~cm}^{-1}$ is observed only for irradiated samples (Fig. 3), and which is attributed to the stretching vibration of $\mathrm{O}_{2}$ molecules [30]. One can see a weak evolution of the $\mathrm{Q}^{3} / \mathrm{Q}^{2}$ ratio and of the production of molecular oxygen (band at 1550 $\mathrm{cm}^{-1}$ ). It is interesting to notice that the evolution is gradually reduced by increasing the chromium content, leading to its complete disappearance for $0.7 \mathrm{~mol} \%$ of chromium oxide. Irradiation also influences the Raman bands at 850 and $900 \mathrm{~cm}^{-1}$, which were attributed to crystallized chromium oxides. These bands either disappear under irradiation, or are initially completely negligible, as for the case of the glass doped with $0.7 \mathrm{~mol} \%$ of $\mathrm{Cr}_{2} \mathrm{O}_{3}$.

It is known that chromium is a polyvalent ion and exhibits different valence states: "+2", “+3", “+4", " $+5 "$ and " $+6 "$ [31-32]. Among these, only two charge states are paramagnetic: $\mathrm{Cr}^{3+}(\mathrm{S}=3 / 2)$ and $\mathrm{Cr}^{5+}(\mathrm{S}=1 / 2)$. EPR studies of $\mathrm{Cr}^{3+}$ ions in glasses have been presented in many reports [33-36]. The EPR spectrum of pristine aluminoborosilicate glass consists of two EPR lines located at $\mathrm{g} \sim 5.0$ and at $\mathrm{g} \sim 1.98$ (Fig. 4). We observed that an increase in the total concentration of chromium oxide up to $0.69 \mathrm{~mol} \%$ is accompanied by an increase in the intensity of the signal at $\mathrm{g} \sim 5.0$ (Fig. 4). Conversely, the EPR signal intensity at $\mathrm{g} \sim 1.98$ decreases with increasing chromium concentration, eventually resulting in a complete disappearance at the highest $\mathrm{Cr}$ content of 0.31 and $0.69 \mathrm{~mol} \%$ (inset in the Fig. 4). Exposure to $\beta$-radiation leads to a decrease of the EPR signal intensity (at $g \sim 5$ ) that is dependent on the chromium concentration (Fig. 5a), which implies a decrease of the quantity of $\mathrm{Cr}^{3+}$ ions diluted in the glass, and therefore the reduction of $\mathrm{Cr}^{3+}$ states to $\mathrm{Cr}^{2+}$ states. Under irradiation, a new line at $\mathrm{g} \sim 1.97$ arises (Fig. 5b), which is assigned to isolated $\mathrm{Cr}^{5+}\left(3 \mathrm{~d}^{1},{ }^{2} \mathrm{D}_{3 / 2}\right)$ ions [3738]. The increase of the amplitude of this line with $\mathrm{Cr}_{2} \mathrm{O}_{3}$ concentration suggests an increase in the number of $\mathrm{Cr}^{5+}$ centres with irradiation. This result indicates the occurrence of the 
reduction of $\mathrm{Cr}^{6+}$ to $\mathrm{Cr}^{5+}$ for all concentrations of $\mathrm{Cr}$-doping in the irradiated glasses. Fig. 6 presents the dependence of the EPR signal (corresponding to the paramagnetic defects created during irradiation) on chromium concentration. One can see from Fig.6a that the defect content decreases with the concentration of chromium oxide, and eventually disappears for concentrations higher than $0.31 \mathrm{~mol} \%$.

\subsection{Modification of Mn environment under irradiation}

The presence of isolated $\mathrm{Mn}^{2+}$ ions $(\mathrm{S}=5 / 2, \mathrm{I}=5 / 2)$ in a glass is easily detected by EPR spectroscopy as a hyperfine structure (6 lines) at $g \sim 2$ [39]. The EPR spectrum of pristine aluminoborosilicate glasses doped with manganese (Fig. 7a) consists of a symmetric EPR line at $\mathrm{g} \sim 2.0$, a very small signal at $\mathrm{g} \sim 4.3$, and a distinct shoulder at $\mathrm{g} \sim 3.3$. It can be seen that the intensity of the signal at $\mathrm{g} \sim 2$ increases with manganese concentration. This fact indicates that during glass synthesis, $\mathrm{Mn}^{3+}$ is converted to the $\mathrm{Mn}^{2+}$ state. It can be also seen in Fig. 7a that an increase in the total manganese content results in the disappearance of the hyperfine EPR signal structure due to the dipole-dipole interactions between $\mathrm{Mn}^{2+}$ ions. A weak $\mathrm{Mn}-$ concentration-dependent EPR line at $\mathrm{g} \sim 4.3$ has been attributed to $\mathrm{Mn}^{2+}$ ions located at other sites in the glass [40].

The intensity of the EPR line at $\mathrm{g} \sim 2$ is higher for the irradiated glasses in comparison with the pristine one (Fig. 7a) but the width of the band is not significantly modified (Fig.7b), implying an increase in the number of isolated $\mathrm{Mn}^{2+}$ ions. Thus, it can be concluded that irradiation affects the valence state of $\mathrm{Mn}^{3+}$ ions.

In irradiated aluminoborosilicate glasses, the EPR signal at $\mathrm{g} \sim 2$ has been attributed to paramagnetic defects formed during irradiation [6]. As one can see from Fig.7b, the amount of defects created under irradiation diminishes with increasing manganese concentration, and saturates at concentrations higher than $0.30 \mathrm{~mol} \%$. 


\subsection{Modification of $N d$ and Ce environments under irradiation}

It is well known that the presence of paramagnetic $\mathrm{Nd}$ and $\mathrm{Ce}$ ions can only be detected at low temperature [41]. As well, in a previous study, we observed that RE reduction occurs under irradiation [42]. As the symmetry of the ligand field surrounding the $\mathrm{Nd}^{3+}$ ion can be discerned from any Stark splitting that occurs [22], we have used luminescence spectroscopy to examine re-arrangements in the surroundings of the $\mathrm{Nd}^{3+}$ ions. The splitting energy is representative of the ${ }^{4} \mathrm{~F}_{3 / 2}-{ }^{4} \mathrm{I}_{9 / 2}$ band peak positions. De-convolution of the band into Gaussian functions was performed for all glass samples, as it is shown in inset of Fig. 8. Each spectrum was fitted in the region from 850 to $950 \mathrm{~nm}$, assuming splitting into five Stark components, but without any restrictions on peak intensity, position or width. As shown in Fig.9, for the lowest doses (between $5.10^{6}$ and $8.10^{8}$ Gy), the Stark splitting energy $\left(\Delta I_{2}\right)$ of the ${ }^{4} I_{9 / 2}$ levels fluctuates about an average value, revealing only slight changes in the surroundings of the $\mathrm{Nd}^{3+}$ ion. The increase in the value of $\left(\Delta I_{2}\right)$ becomes significant only for the highest dose.

As previously mentioned, the defects produced in these simplified glasses under ionizing radiation are - in most cases - holes trapped on oxygen sites [6]. It is seen in Fig. 9 that the defect quantity in the glass decreases with the concentration of rare earth elements,and the rate of this decrease depends on the type of RE dopant. In particular, the addition of a small amount of cerium oxide to the glass $(0.08 \mathrm{~mol} \%)$ is almost equivalent to the highest concentration of neodymium oxide $\left(0.8 \mathrm{~mol} \%\right.$ of $\left.\mathrm{Nd}_{2} \mathrm{O}_{3}\right)$ in terms of defect quantity suppression after a given dose of irradiation (Fig. 9).

\subsection{Structural modifications under irradiation in aluminoborosilicate glasses doped with Ce} and $N d$ 
Fig. 10a presents the Raman spectra of non-irradiated and irradiated glasses doped with the lowest and the highest concentrations of $\mathrm{Nd}$ and $\mathrm{Ce}$ ions. One can see that for the low $\mathrm{RE}$ concentration, structural modifications under irradiation are similar to those observed in undoped glasses [5]. Firstly, we observe that the intense band at $480 \mathrm{~cm}^{-1}$ attributed to vibration Si-O-Si modes shifts towards higher frequencies with irradiation, indicating a reduction of the mean bond angle. Second, an increased amount of polymerization is discerned by the increase in the $Q^{3} / Q^{2}$ species ratio. The production of molecular oxygen under irradiation (Raman peak at $\sim 1550 \mathrm{~cm}^{-1}$ ) could not be analyzed because of the polishing of the glass surface. According to a detailed analysis [43], molecular oxygen is mainly located within the first $50 \mu \mathrm{m}$ under the glass surface, with the $\mathrm{O}_{2}$ layer thickness depending on the radiation dose and on the glass composition.

We examined the shift of the Si-O-Si bending modes as a function of the RE concentration for both $\mathrm{Nd}$ and Ce-doped glass (Fig. 10b), and different behaviour was observed for each of the two dopants. In the glasses doped with Nd ions, the Raman shift of the Si-O-Si modes is independent of $\mathrm{Nd}$ concentration. However, in the case of Ce doping, the same Raman shift is greatly influenced by the Ce concentration (Fig. 10b).

\subsection{Gas production in irradiated aluminoborosilicate glass}

In un-doped simplified nuclear glasses, two processes participate predominantly in the production of dissolved molecular oxygen during irradiation. The first process is the increased level of polymerization linked to the migration of alkalines - which act as modifiers - in the vitreous network. The second process is the transformation of a portion of the tetrahedrallybonded boron $\left(\mathrm{BO}_{4}\right)$ into a trigonal bonding configuration $\left(\mathrm{BO}_{3}\right)$; this process is again correlated with the migration of alkalines, here acting as charge compensators [5]. It was shown [49] that dose, dose rate, and irradiation temperature have an influence on molecular 
oxygen production. Simultaneously, the presence of dopants in the glass also changed the $\mathrm{O}_{2}$ quantity. We therefore estimated the area under the Raman peak corresponding to molecular oxygen $\left(1550 \mathrm{~cm}^{-1}\right)$ in aluminoborosilicate glasses doped with $\mathrm{Cr}$ ions (Fig.3). With increasing chromium concentration (Fig. 11), one can see a decrease in the quantity of molecular oxygen produced in these glasses during an irradiation of $1.6 .10^{9} \mathrm{~Gy}$. Other types of gas production were examined through experiments using $\gamma$-irradiation (at a level of $7.10^{6}$ Gy) of the glass powder placed in a sealed tube. These experiments were carried out on simplified nuclear glasses (aluminoborosilicate) doped with $\mathrm{Sm}_{2} \mathrm{O}_{3}$. Even at these weak doses, we clearly observed the production of different gases such as $\mathrm{CO}$ and $\mathrm{CO}_{2}$, which could be linked to the reduction of $\mathrm{Sm}^{3+}$ at these doses (table 1). Future work will present the use of the same type of experiment to detect gas production during $\beta$-irradiation, and will analyze the effect of gas production at doses that result in the complete reduction of $\mathrm{Sm}^{3+}$ to $\mathrm{Sm}^{2+}$.

\section{Discussion}

The long-term durability of oxide glasses is a crucial issue because these materials are designed as matrices to host a variety of toxic and/or radioactive ions. Since some dopant elements (transition and/or rare-earth elements) exist as a fission products (appearing due to $\alpha, \beta$ and $\gamma$ disintegrations during long-term storage) or play the role of non-radioactive actinide surrogates, the exploration of structural changes in irradiated oxide glasses by introducing $\mathrm{TM}$ or $\mathrm{RE}$ ions can give an additional information about the confinement properties of nuclear glasses.

\subsection{Structural modifications in Cr-doped oxide glasses}


The Raman study presented above showed that Cr-doped silicate and aluminoborosilicate glasses did not reveal significant modifications in glass structure (Fig.1 and 2). The absence of any changes in the relative proportions of $\mathrm{Q}^{2}$ and $\mathrm{Q}^{3}$ species implies no occurrence of a depolymerization effect (increase of $\mathrm{Q}^{2} / \mathrm{Q}^{3}$ ratio, as occurs in the case of iron doping [18]) nor a polymerization effect (increase of $\mathrm{Q}^{3} / \mathrm{Q}^{2}$ ratio, as in the case of $\mathrm{RE}$ doping) with addition of chromium ions to these glasses. However, the increased chromium concentration leads to new bands at 845 and $900 \mathrm{~cm}^{-1}$ corresponding to the vibration modes of crystallized chromium oxides [26,27]. We can therefore conclude that chromium doping increases the activation energy of crystallization.

The changes in the Raman spectra of the glasses after irradiation (Fig.3) are typical for undoped oxide glasses [5]. The shift of the Si-O-Si bending vibration modes (band at $480 \mathrm{~cm}^{-1}$ ) attests to the densification of the glass structure, and the increase of the $\mathrm{Q}^{3} / \mathrm{Q}^{2}$ ratio indicates an increase in the glass polymerization. These modifications all become less prominent with increasing $\mathrm{Cr}$ concentration (Fig.3), but are noticeable up to $0.31 \mathrm{~mol} \%$ of $\mathrm{Cr}_{2} \mathrm{O}_{3}$. Such behaviour shows that $\mathrm{Cr}^{3+}$ ions are incorporated into the glasses as a modifier ion [44].

In summary, the addition of chromium to the glass matrix diminishes the occurrence of structural modifications under ionizing radiation. This effect has been previously observed for glasses doped with iron [18]. We attribute the decreased structural evolution during irradiation to the restriction of alkaline mobility due to the presence of transition elements such as chromium.

The $\mathrm{Cr}^{3+}$ EPR spectra of numerous vitreous systems have been reported [33-38,40, 45-48]. The EPR spectrum of Cr-doped silicate glass exhibits two resonances at $\mathrm{g} \sim 5.0$ and $\mathrm{g} \sim 1.98$ (Fig. 4). The $\mathrm{g} \sim 5.0$ signal is attributed to isolated $\mathrm{Cr}^{3+}$ ions, but the origin of the band at $\mathrm{g} \sim$ 1.98 is not attributed so unequivocally. The EPR study of $3 \mathrm{~B}_{2} \mathrm{O}_{3} \cdot \mathrm{PbO}$ glasses revealed the presence of both $\mathrm{Cr}^{3+}(\mathrm{g} \sim 5.1)$ and $\mathrm{Cr}^{5+}(\mathrm{g} \sim 1.97)$ species [49]. The $\mathrm{g} \sim 1.98$ EPR signal 
caused by $\mathrm{Cr}^{5+}$ ions was also detected in soda-lime-silicate glass fiber [46] and other oxide glasses containing $\mathrm{Cr}$ ions [47-48]. The appearance of the band at $\mathrm{g} \sim 1.98$ is often attributed to the coupling of $\mathrm{Cr}^{3+}$ cations $[36,45]$, although some authors consider its origin to be isolated $\mathrm{Cr}^{3+}$ ions located at sites other than presented by the $\mathrm{g} \sim 5$ signal $[33-34,46-48]$. Since the EPR intensity of this band diminishes for the heavily doped sample (inset in Fig. 4), the attribution of this band to $\mathrm{Cr}^{3+}-\mathrm{Cr}^{3+}$ coupled pairs seems to be refuted. However, a small component appearing as a hump on the low field side of the band at $\mathrm{g} \sim 1.98$ can be assigned to exchange-coupled pairs of $\mathrm{Cr}^{3+}$ ions (Fig. 4). Therefore, the EPR analysis of pristine $\mathrm{Cr}$ doped silicate glass implies that $\mathrm{Cr}^{3+}$ ions have more than one paramagnetic site in this matrix and they can be considered as $\mathrm{Cr}^{3+}$ pairs coupled by magnetic superexchange interactions.

Under irradiation, the intensity of the bands at $\mathrm{g} \sim 5.0$ as well as at $\mathrm{g} \sim 1.98$ is observed to decrease (Fig. 5a and 5b) and new lines at $\mathrm{g} \sim 2$ and $\mathrm{g} \sim 1.97$ appear. The first one is assigned to the paramagnetic defects produced under irradiation [6], the second one is consistent with the presence of $\mathrm{Cr}^{5+}$ ions [12]. Signals from chromium in its four valence states, $\mathrm{Cr}^{3+}, \mathrm{Cr}^{4+}$, $\mathrm{Cr}^{5+}$ and $\mathrm{Cr}^{6+}$, have been seen in the spectral characteristics of $\mathrm{ZrO}_{2}-\mathrm{Al}_{2} \mathrm{O}_{3}-\mathrm{SiO}_{2}, \mathrm{Li}_{2} \mathrm{~B}_{4} \mathrm{O}_{7}$ and silica sol-gel glasses [31-32]. In their absorption spectra, pristine $\mathrm{Cr}$ doped silicate glasses reveal the presence of both $\mathrm{Cr}^{3+}$ and $\mathrm{Cr}^{6+}$ ions [12]. In irradiated $\mathrm{Cr}$-doped silicate and borosilicate glasses, $\mathrm{Cr}^{4+}$ and $\mathrm{Cr}^{5+}$ ions have also been detected. As can be seen from Fig. 5a and $5 \mathrm{~b}$, irradiation leads to a decrease in the quantity of $\mathrm{Cr}^{3+}$ ions (shown by the decreased intensity of the EPR signal at $\mathrm{g} \sim 5$ ) and simultaneously to an increase in the amount of $\mathrm{Cr}^{5+}$ ions (the increase of the line at $g \sim 1.97$ ). This implies that irradiation affects the valence state of the chromium ions, and clearly reveals the reduction of $\mathrm{Cr}^{6+}$ ion $\left(\mathrm{Cr}^{6+} \rightarrow \mathrm{Cr}^{5+}\right.$ or $\mathrm{Cr}^{6+} \rightarrow$ $\left.\mathrm{Cr}^{4+}[12]\right)$. However, since $\mathrm{Cr}$ enters the glass predominantly as $\mathrm{Cr}^{3+}$ ions, it is expected that under irradiation, the following reactions will take place: $\mathrm{Cr}^{3+}+$ hole $\rightarrow \mathrm{Cr}^{4+}, \mathrm{Cr}^{3+}+$ electron 
$\rightarrow \mathrm{Cr}^{2+}$. Therefore, the changes in the quantity of $\mathrm{Cr}^{3+}$ can be linked to processes of either $\mathrm{Cr}^{2+}$ or $\mathrm{Cr}^{4+}$ ion formation.

Recently, it has been shown for RE [16-17,42] and iron-doped [18] oxide glasses that the amount of defects produced under irradiation (EPR line at $\mathrm{g} \sim 2$ ) is decreased or completely suppressed (as in the case of iron doping) by increased dopant concentration. In Fig. 6, a decreased defect density can be seen beginning at $0.31 \mathrm{~mol} \%$ of chromium oxide. Thus, it is once again confirmed that the addition of transition elements diminishes or even annihilates the production of defects in glasses under irradiation.

\subsection{EPR study of Mn-doped oxide glass}

Investigations of the EPR spectra of Mn-doped aluminoborosilicate glass have shown that the spectra are characterized by an intense resonance signal at $\mathrm{g} \sim 2$ with a weak but discernable hyperfine structure, as well as an absorption around $\mathrm{g} \sim 4.3$ (Fig. 7a). These bands are

attributed to $\mathrm{Mn}^{2+}$ ions situated at different sites in the glass [40,50]. It is known that in silicate and germanate glasses, manganese ions exists in the $\mathrm{Mn}^{2+}$ state with both octahedral and tetrahedral coordination [50], as was also shown by Menassa and Simkin [51]

In addition, the luminescence analysis of sodium borosilicate glasses presented in [51] revealed that in these glasses, $\mathrm{Mn}^{2+}$ ion occupies two sites: one octahedral and the other tetrahedral. Along with these conclusions, the authors showed that tetrahedral $\mathrm{Mn}^{2+}$ ions are dissolved mainly in the Si-rich phase, while octahedrally-coordinated manganese is located primarily in the B-rich phase [51].

Our EPR data on irradiated Mn-doped aluminoborosilicate glass (Fig. 7a) suggest that irradiation affects the valence state of manganese ions and results in an increased quantity of $\mathrm{Mn}^{2+}$ ions. One can see from Fig $7 \mathrm{~b}$ that the defect production under irradiation is completely suppressed in the presence of manganese ions with a concentration higher than $0.30 \mathrm{~mol} \%$. 
The tendency of the defect production blockage in Mn-doped aluminoborosilicate glass is observed again, just as in the case of Fe or Cr doping.

\subsection{Structural modifications in RE-doped oxide glasses}

Irradiation of RE-doped aluminoborosilicate glass affects not only the valence state of doping ions, but also leads to re-arrangements in the environments of the RE elements and to the appearance of different RE sites inside the glass [16-17]. As our recent study showed [42], the presence of a reduction process in the case of $\mathrm{Nd}$-doping is not as evident as for Ce-doped glasses, but the changes in the local surroundings of $\mathrm{Nd}^{3+}$ ion during irradiation can be confirmed by the detailed consideration of luminescence data. Indeed, when observing the evolution in the luminescence spectrum of $\mathrm{Nd}$-doped aluminoborosilicate glass with increasing irradiation dose, one can clearly identify a change in the Stark splitting (Fig.8). It can be seen from this figure that the Stark splitting increases with greater dose, suggesting the occurrence of structural variations in the local environment of $\mathrm{Nd}^{3+}$ ions in the glass matrix. The existence of multiple $\mathrm{Nd}^{3+}$ sites in glasses was discussed in [52-53], and our previous investigations on Gd-doped glass also clearly showed that $\mathrm{Gd}^{3+}$ ions can occupy two sites: both a network modifier and a network former site [16].

Figure 9 depicts the evolution of the total concentration of defects as analyzed by EPR spectroscopy as a function of dopant concentration for all the rare earth elements studied, as well as for all doses of radiation used. One can see in this figure that the addition of rare earth ions into the glass tends to decrease the amount of defects created under irradiation, and this decrease is significantly more evident and rapid in the case of Ce-doped glass. The process leading to the defect quantity decrease/suppression has been described as the consecutive trapping of charge carriers (electron-hole pairs) supporting the dynamical balance between the two charge states of RE or TM ions [16-18,42]. Therefore, the reduction process seems to be 
linked to both the defect creation and the structural modification of the glass under irradiation. The restriction of defect production under irradiation leads to a decrease of alkaline migration [15], and it was shown [5] that structural modifications are also correlated with alkaline migration in glasses under irradiation. One can see (Fig. 10a) that structural changes in irradiated Ce- and Nd-doped glasses are decreased but not suppressed, and again, the observed decrease (Fig.10b) is more rapid and significant in the case of Ce-doped glass. This process occurs in a similar manner as that for defects. Fig. 9 shows that the defect quantity is drastically decreased in the case of Ce-doped glass. Therefore, we conclude that glass densification, increased polymerization, $\mathrm{Na}$ migration, and the restriction of the defect creation in the glass are consistent with a Ce-reduction process under irradiation. On the other hand, in the glasses doped with $\mathrm{Nd}$ ions, no significant difference in structural modification under irradiation was observed (Fig.10a,b). In this case, we observed a weak decrease in defect production, but which does not limit for the alkaline ion migration. It can therefore be concluded that the structural evolution of the glass - as well as the evolution of the defect production - depend on both the relative stability of the RE valence state and on the ability of the RE element to be reduced (Fig. 9 and 10b).

\subsection{Production of molecular oxygen}

The formation of dissolved molecular oxygen under $\beta$-irradiation in oxide glasses has been reported in $[5,13]$. Raman studies have shown that molecular oxygen is formed due to alkaline migration resulting in an increase in glass polymerization [13]. One can see from Fig. 11 that TM doping has a strong influence on the formation of molecular oxygen. With increased TM concentration, the observed amount of oxygen decreases, prompting the assumption of some relationship between these two processes. This relationship is provided by the restriction of alkaline migration when doping with transition elements. In addition, for the highest 
concentration of dopants, the presence of some amount of molecular oxygen is still observed, while other structural modifications (namely defect production, increase of glass polymerization and densification) are completely suppressed. The residue of molecular oxygen could consequently be a sign of some process compensating the reduction of $\mathrm{Fe}^{3+}$, $\mathrm{Cr}^{6+}$ and $\mathrm{Cr}^{3+}$ ions under ionizing radiation.

In summary, we have shown that doping with the transition as well as the rare earth elements leads to a restriction of structural evolution in oxide glasses under ionizing radiation. In particular, it seems that the polyvalence of certain dopants and the relative stability of different charge states are the primary criteria in determining the increased resistance to ionizing radiation of the glasses studied. We noticed, however, a difference between doping by rare earth or transition elements, despite the identical stability of their redox states (couples $\mathrm{Fe}^{2+} / \mathrm{Fe}^{3+}$ and $\mathrm{Sm}^{2+} / \mathrm{Sm}^{3+}$, for instance) [17,18]. It is known that the electronic structures of these two families of cations are different, and this may be the origin of the difference in their behaviour. The d-orbitals of TM atoms or ions are rather peripheral, and therefore, their electrons are sensitive to nearby environments. Simultaneously, the d-electrons themselves strongly influence neighbouring atoms and ions. Conversely, 4f-electrons are located deep inside the electronic shell of the RE atom or ion, and thus are strongly shielded by the external 5 s-and 5 p-electrons. Therefore, any interaction of the 4 f-electrons with the neighbouring atoms or ions is weaker, as is their influence on the properties of their surroundings. Consequently, the effect of embedded RE elements on modifications in the oxide glass structure is less pronounced than for TM elements.

\section{Conclusion}

In this paper, we have presented further study of the effect of TM and RE doping on structural modifications in oxide glasses under ionizing radiation. We have observed a restriction of 
structural changes and decreased defect production under ionizing radiation in case of $\mathrm{Nd}$ and Ce doping, and their complete suppression in case of $\mathrm{Cr}$ and $\mathrm{Mn}$ doping. It was shown that modifications in the dopant environment - in particular their reduction processes - depend on the ion valence state stability and the ability of the ion to change its charge state under irradiation. It is noted that the efficiency of the reduction process (electron trapping) does not track the efficiency of defect production (mainly, hole trapping) under irradiation. The observation of gas production during irradiation $\left(\mathrm{O}_{2}, \mathrm{CO}, \mathrm{CO}_{2}\right)$ leads us to propose that the oxidation of oxygen in the vitreous network is the structural mechanism that compensates the reduction of the transition and rare earth elements.

\section{Acknowledgements}

We are grateful to Thierry Pouthier and Stephane Esnouf for their contribution during external $\beta$ irradiation experiments. We also thank Gilles Montagnac and Bruno Reynard (Laboratoire des Sciences de la Terre, ENS Lyon, France) for assistance in Raman experiments.

\section{References}

[1] Plodinec M J 1986 J. Non-Cryst. Solids 84206

[2] Jantzen C M 1986 J. Non-Cryst. Solids 84215

[3] Bonfils J, Panczer G, Ligny D, Peuget S and Champagnon B, 2007 J. Nucl. Mater. 362 480

[4] Weber W 1988 J. Nucl.Instr. and Meth. B 32471

[5] Boizot B, Petite G, Ghaleb D, Reynard B, Calas G 1999 J. Non-Cryst. Solids 243268

[6] Boizot B, Petite G, Ghaleb D, Calas G 1998 Nucl. Instr. and Meth. B 141580

[7] Dutt D A, Higby P L and Griscom D L 1991 J. Non-Cryst. Solids 13041 
[8] Weeks R A 1994 J. Non-Cryst. Solids 1791

[9] Griscom D L 1984 J. Non-Cryst. Solids 64229

[10] Kordas G, Camara B and Oel H J 1982 J. Non-Cryst. Solids 5079

[11] Griscom D L 1973 J. Non-Cryst. Solids 1325

[12] Ollier N, Champagnon B, Boizot B, Guyot Y, Panczer G, Padlyak B 2003 J. Non-Cryst.

Solids $\mathbf{3 2 3} 200$

[13] Boizot B, Petite G, Ghaleb D, Pellerin N, Fayon F, Reynard B, Calas G 2000 Nucl. Instr. and Meth. B 166-167 500

[14] Abbas A, Serruys Y, Ghaleb D Delaye J-M, Boizot B, Reynard B 2000 Nucl. Instr. and Meth. B 166-167 445

[15] Boizot B, Ollier N, Olivier F, Petite G, Ghaleb D, Malchukova E 2005 Nucl. Instr. and Meth. B 240146

[16] Malchukova E, Boizot B, Ghaleb D, Petite G 2006 J. Non-Cryst. Solids 352297

[17] Malchukova E, Boizot B, Petite G, Ghaleb D 2007 J. Non-Cryst. Solids 3532397

[18] Olivier F Y, Boizot B, Ghaleb D, Petite G 2005 J. Non-Cryst. Solids 3511061

[19] Haddi A, Farges F, Trocellier P, Curti E, Harfouche M and Brown G E 2006 Proceedings of $13^{\text {th }}$ Conference on X-Ray Absorption Fine Structure (XAFS13), July 9-14, 2006 Stanford California

[20] Deja J 2002 Cement and Concrete Research 321971

[21] Li H, Vienna J D, Smith D E, Hrma P, Gong M 1997 Ceram. Trans. 72399

[22] Li H, Li L, Vienna J D, Quian M, Wang Z, Darab J G, Peeler D K 2000 J. Non-Cryst. Solids. 278. 35

[23] Lopez C, Deschanels X, Bart J M, Boubals J M, den Auwer C and Simoni E 2003 J. Nucl. Mater. 31276

[24] Loiseau P, Cauran D, Baffier N, Mazerolles L and Fillet C 2004 J. Nucl. Mater. 33514 
[25] France P W, Carter S F, Parker J M 1986 Phys. Chem. Glasses. 2732

[26] Hollis D B, Turner D, Mosselmans J F 1997 Nucl. Instr. and Meth. in Phys. Res. B . 133

62

[27] McMillan P F 1984 Am. Mineral 69622

[28] Sykes D and Kubicki J D 1996 Am. Mineral 81265

[29] Pasquarello A and Car R 1998 Phys. Rev. Lett. 805145

[30] Colthup N B, Daly L H and.Wiberley S E 1990 In "Introduction to Infrared and Raman Spectroscopy" (Academic press)

[31] Koepke Cz, Wisniewski K, Grinberg M, 2002 J. Alloys Compd. 34119

[32] Sterk W, Deren P J, Lukowiak E, Hanuza J, Frulis H, Bednarkiewicz, Gaishun V $2001 \mathrm{~J}$. Non-Cryst. Solids 28856

[33] Rao A S, Rao J L, Reddy R R, Rao T V R 1995 Opt. Materials. 4717

[34] Costa V C, Lameiras F S, Pinheiro M V B, Sousa D F, Nunes L A O, Shen Y R, Bray K L 2000 J. Non-Cryst. Solids . 273209

[35] Harris E A 1987 Phys. Chem. Glasses 28. 196

[36] Dance J M, Videau J J, Portier J 1986 J. Non-Cryst. Solids 8688

[37] B.V. Padlyak, J. Kornatowski, G. Zadro_zna, M. Rozwadowski, A. Gutsze, 2000 J. Phys. Chem. A 10411837

[38] J.T. Fournier, R.J. Landry, 1971 J. Chem. Phys. 552522

[39] Faber A J, van Die A, Blasse G, van der Weg W F 1987 Phys. Chem. Glasses 28150

[40] Bogomolova L D, Grechko E G, Krasil'nikova N A, Sakhrov V V 1985 J. Non-Cryst.

Solids 69299

[41] Mirsa S K, Isber S 1998 Physica B. 253111

[42] Malchukova E, Boizot B, Petite G, Ghaleb D 2007 Phys. Stat. Sol. (c) 4(3)1280

[43] Ollier N, Boizot B, Reynard B, Ghaleb D, Petite G 2005J. of Nucl. Mat.. 340209 
[44] El-Diasty F, Abdel-Baki M, Abdel Wahan F A and Darwish H 2006 Appl. Opt. 457818

[45] Landry R J, Fournier J T, andYoung C G 1967 J. Chem. Phys. 461285

[46] Bruckner R, Sammet N and Stockhorst H 1980 J. Non-Cryst. Solids 40273

[47] Simon S, van der Poll A.,Reijerse E J, Ketgen A P M, Van Moorsel G J M P, and de Boel E 1995 J. Chem. Soc. Faraday Trans. 911519

[48] Cozar O, Ardelean I, Bratu I, Ilonca Gh and Simon S 1993 Solid State Commun. 86569

[49] Ardelean I, Ilonca Gh, Peteanu M,Baernos E and Indrea E 1982 J. Mater.Sci. 171988

[50] Van Die A, Leenaers A C H I, Der Weg W F V, 1988 J. Non-Cryst. Solids 9932

[51] Menassa P E and D J Simkin 1986 J. Lumin. 35223

[52] Koepke C, Wisniewski K, Sikoroski L, Piatkowski D, Kowalska K, Naftaly M 2006 Opt. Mater. 28129

[53] Dymnikov A A, Prezhevuskii A K 1997 J.Non-Cryst.Solids 215183 
Figure captions

Figure 1. Raman spectra of pristine silicate glasses doped with $\mathrm{Cr}_{2} \mathrm{O}_{3}$ as a function of $\mathrm{Cr}$ concentration $(0,0.07,0.13,0.69$ and $1.08 \mathrm{~mol} \%)$.

Figure 2. Raman spectra of pristine aluminoborosilicate glasses doped with $\mathrm{Cr}_{2} \mathrm{O}_{3}$ as a function of $\mathrm{Cr}$ concentration $(0.07,0.14,0.24,0.34,0.70,1.04$ mol\%). Inset - Raman spectra of aluminoborosilicate glasses doped with $1.04 \mathrm{~mol}^{\%}$ of $\mathrm{Cr}_{2} \mathrm{O}_{3}$

Figure 3. Raman spectra of the silicate glasses doped with chromium as a function of $\mathrm{Cr}$ concentration

Figure 4. EPR spectra of pristine silicate glass doped with chromium as a function of $\mathrm{Cr}$ concentration. Inset - zoom on spectral region near $\mathrm{g} \sim 1.98\left(\mathrm{Cr}^{3+}\right.$ band $)$

Figure 5. (a) EPR spectra of silicate glass irradiated with $1.6 .10^{9}$ Gy as a function of $\mathrm{Cr}$ concentration. (b) Influence of chromium concentration on the signal at $g \sim 1.97$ attributed to $\mathrm{Cr}^{5+}$ ion.

Figure 6. EPR spectra of pristine and irradiated (1.6 .10 $\mathrm{Gy}$ ) Cr-doped silicate glass. Influence of chromium concentration on the defect number (at $\mathrm{g} \sim 2$ )

Figure 7. (a) EPR spectra of pristine and irradiated (1.6 .10 $\mathrm{Gy}$ ) aluminiborosilicate glasses doped with $\mathrm{Mn}_{2} \mathrm{O}_{3}$ as a function of manganese concentration. (b) Defect region. The spectra presented are the difference between the derivative of the absorbance of these glasses before and after irradiation.

Figure 8. Evolution of Stark splitting energy $\left({ }^{4} \mathrm{~F}_{3 / 2}-{ }^{4} \mathrm{I}_{9 / 2}\right.$ transition $)$ with irradiation dose. Inset - example of curve fitting to determine splitting energy for each glass

Figure 9. Evolution of defect concentration dependence on nature and concentration of RE dopants $\left(\mathrm{Nd}_{2} \mathrm{O}_{3}, \mathrm{Gd}_{2} \mathrm{O}_{3}, \mathrm{Sm}_{2} \mathrm{O}_{3}, \mathrm{CeO}_{2}\right)$ for all irradiation doses. Line is a guide for the eye. 
Figure 10. (a) Raman spectra of irradiated $\left(2.10^{9}\right.$ Gy) aluminoborosilicate glass and dependence on $\mathrm{Nd}_{2} \mathrm{O}_{3}$ or $\mathrm{CeO}_{2}$ concentration. (b) $\Delta$ Raman shift of Si-O-Si vibration modes of aluminoborosilicate glasses as a function of $\mathrm{Ce}$ or $\mathrm{Nd}$ content. Line is a guide for the eye.

Figure 11. Evolution of Raman spectra near band attributed to molecular oxygen $\left(\mathrm{O}_{2}\right)$ in simplified nuclear glasses irradiated with $2.10^{9}$ Gy as a function of chromium concentration 
Table 1: Gas produced under irradiation $\left(7.10^{6} \mathrm{~Gy}\right)$ in aluminiborosilicate glass doped with 0.17 and 0.5 mol. $\%$ of $\mathrm{Sm}_{2} \mathrm{O}_{3}$

\begin{tabular}{|c|c|c|}
\hline \multirow{2}{*}{$\begin{array}{c}\text { Chemical } \\
\text { combination }\end{array}$} & $0.5 \mathrm{~mol} \%$ & $0.17 \mathrm{~mol} \%$ \\
\cline { 2 - 3 } & $0.34 \%$ & $0.23 \%$ \\
\hline $\mathrm{H}_{2} \%$ & $99.54 \%$ \\
\hline${ }^{4} \mathrm{He}$ & $99.39 \%$ & $45 \mathrm{ppm}$ \\
\hline $\mathrm{CH}_{4}$ & $75 \mathrm{ppm}$ & $5 \mathrm{ppm}$ \\
\hline $\mathrm{C}_{2} \mathrm{H}_{6}$ & $15 \mathrm{ppm}$ & $0.03 \%$ \\
\hline $\mathrm{N}_{2}$ & $0.01 \%$ & $0.06 \%$ \\
\hline $\mathrm{CO}^{2}$ & $0.10 \%$ & $<2 \mathrm{ppm}$ \\
\hline $\mathrm{O}_{2}$ & $<2 \mathrm{ppm}$ & $5 \mathrm{ppm}$ \\
\hline $\mathrm{Ar}$ & $1 \mathrm{ppm}$ & $0.13 \%$ \\
\hline $\mathrm{CO}_{2}$ & $0.14 \%$ & \\
\hline
\end{tabular}




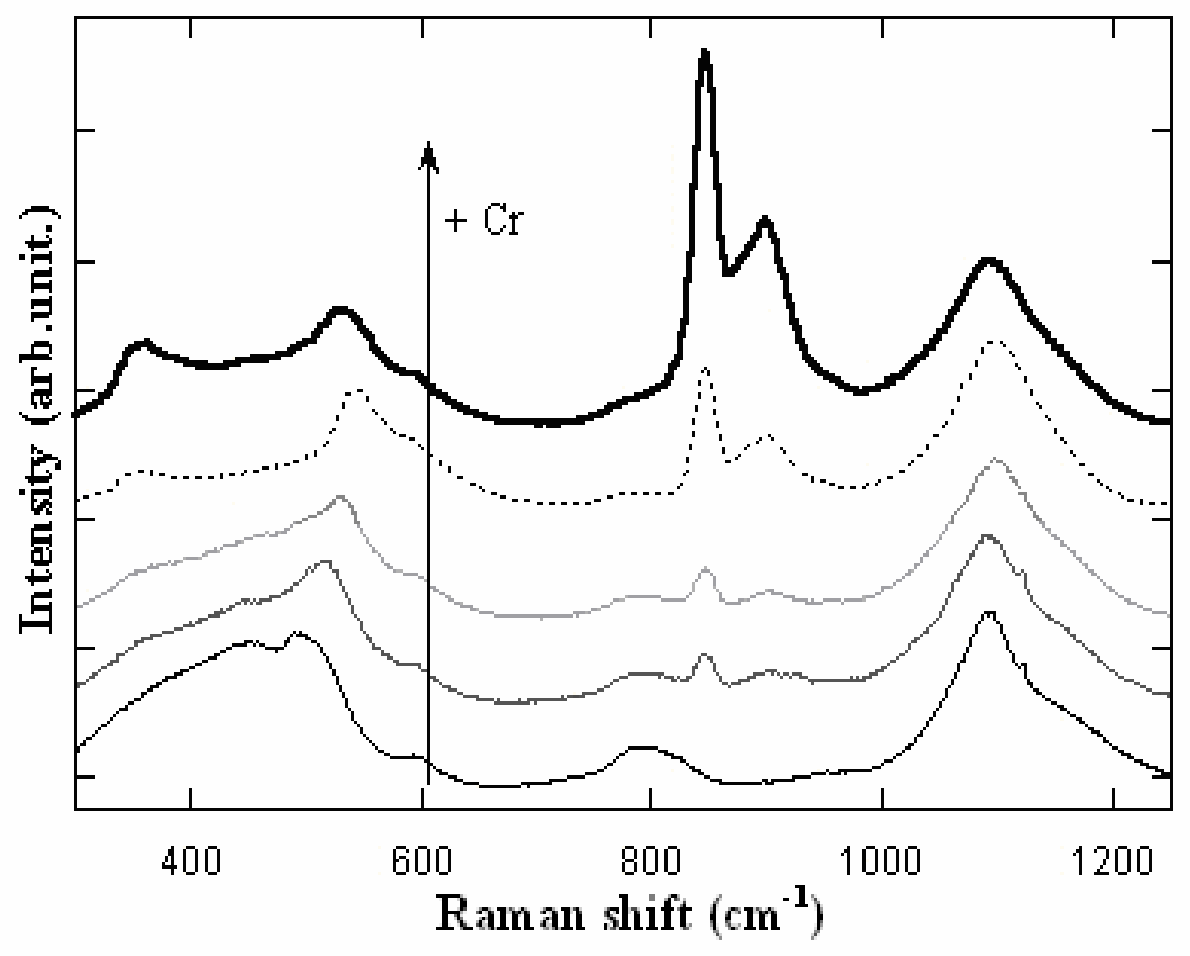

Figure 1. 


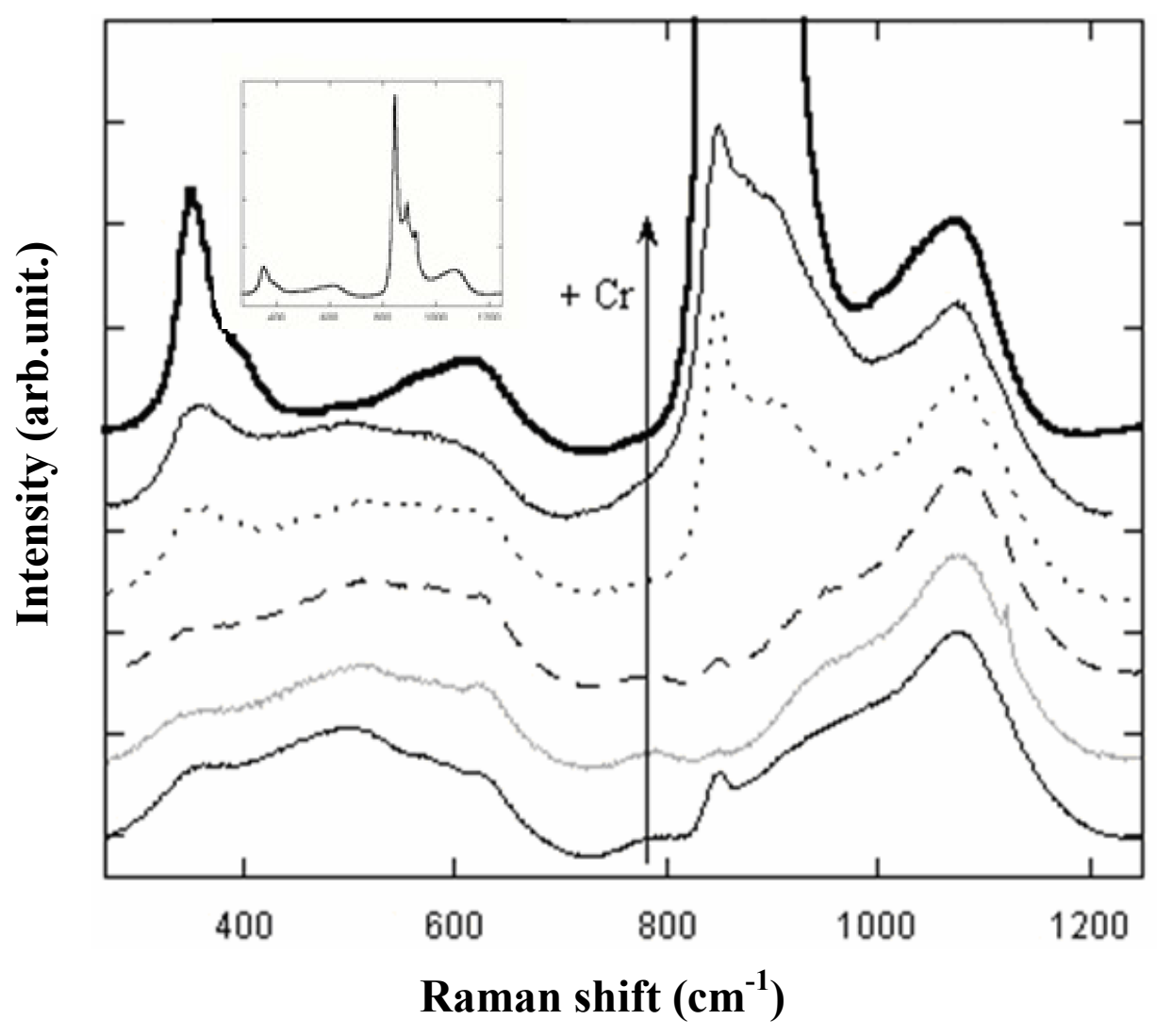

Figure 2. 


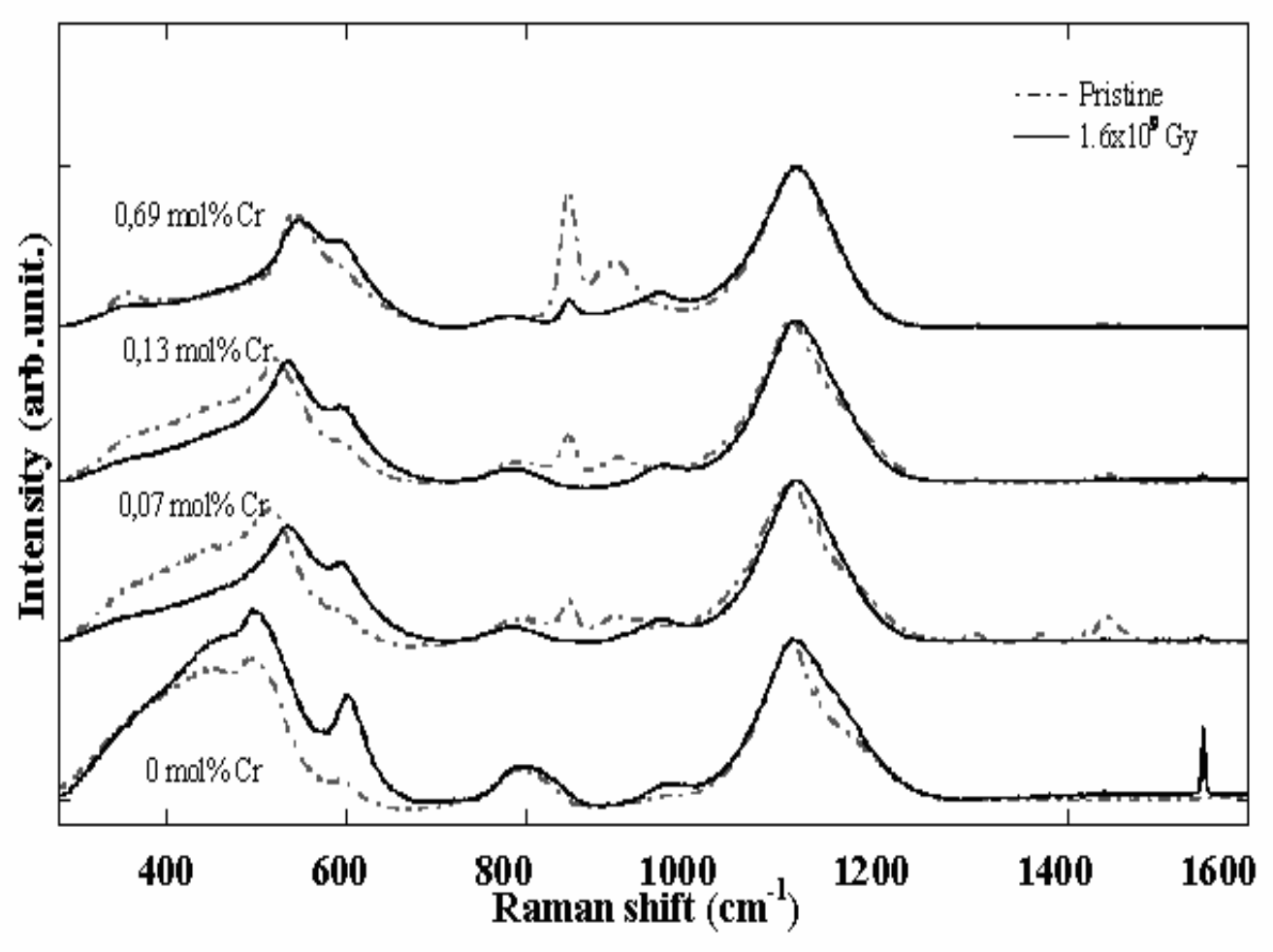

Figure 3. 


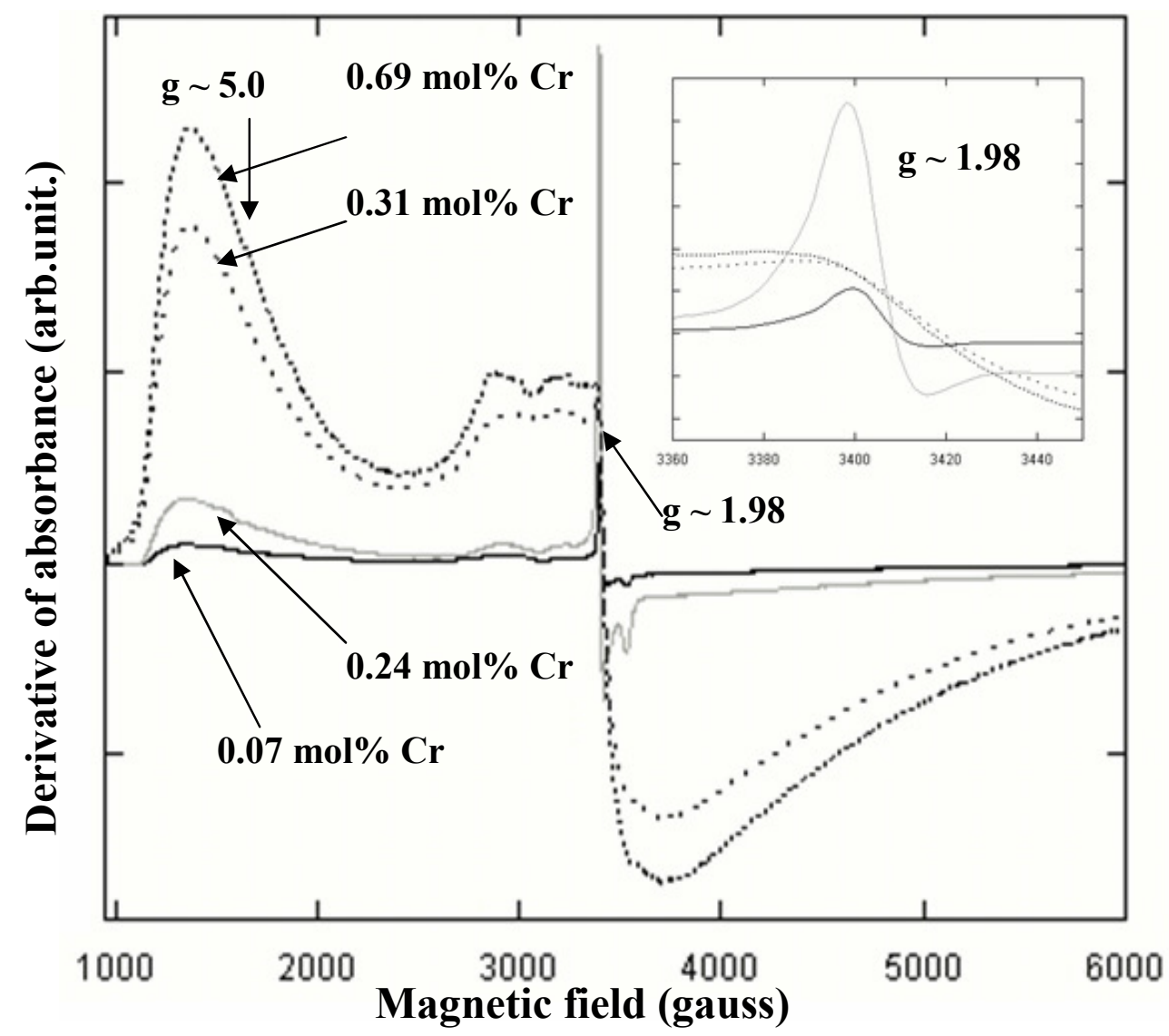

Figure 4. 


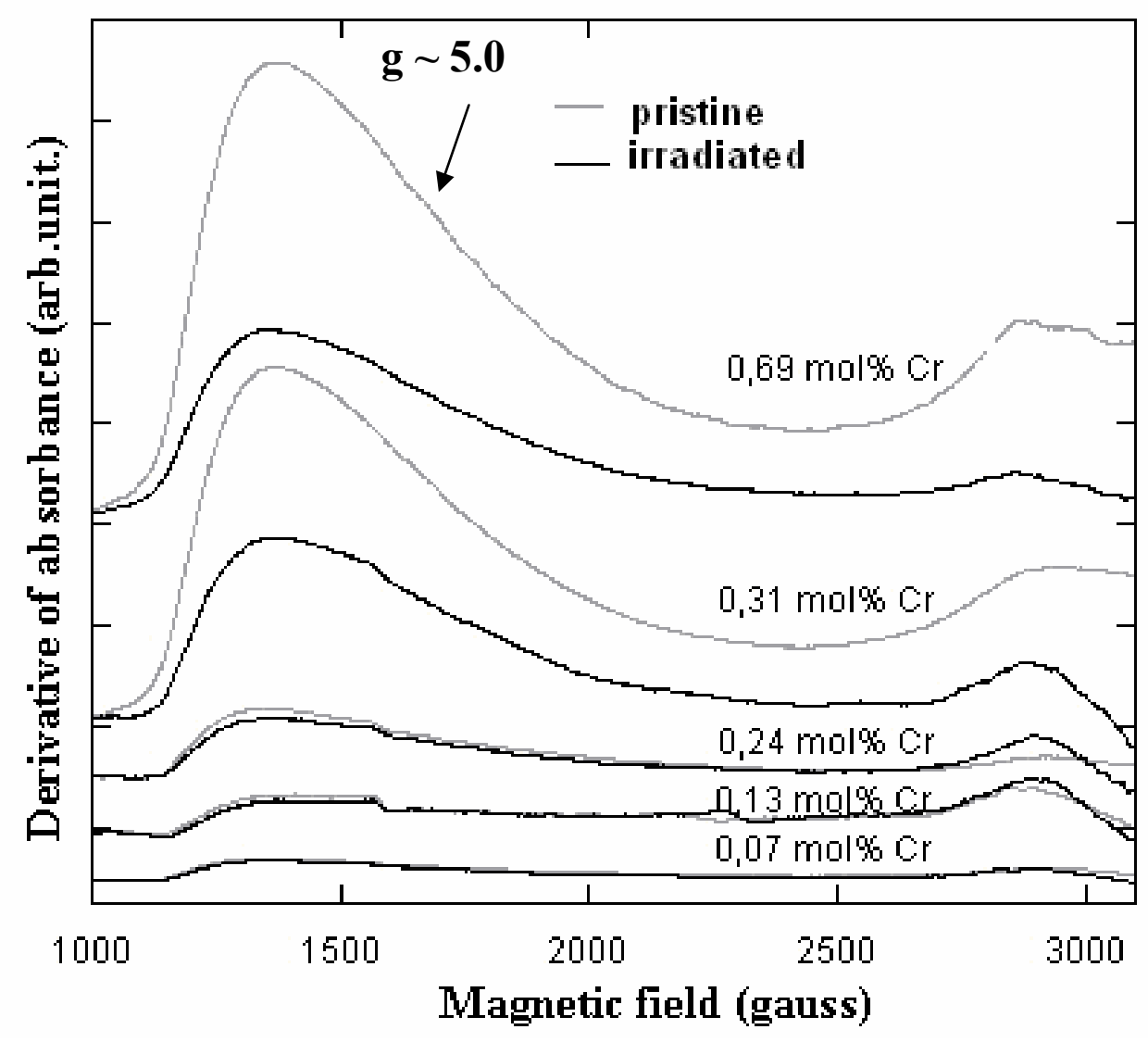

Figure 5a. 


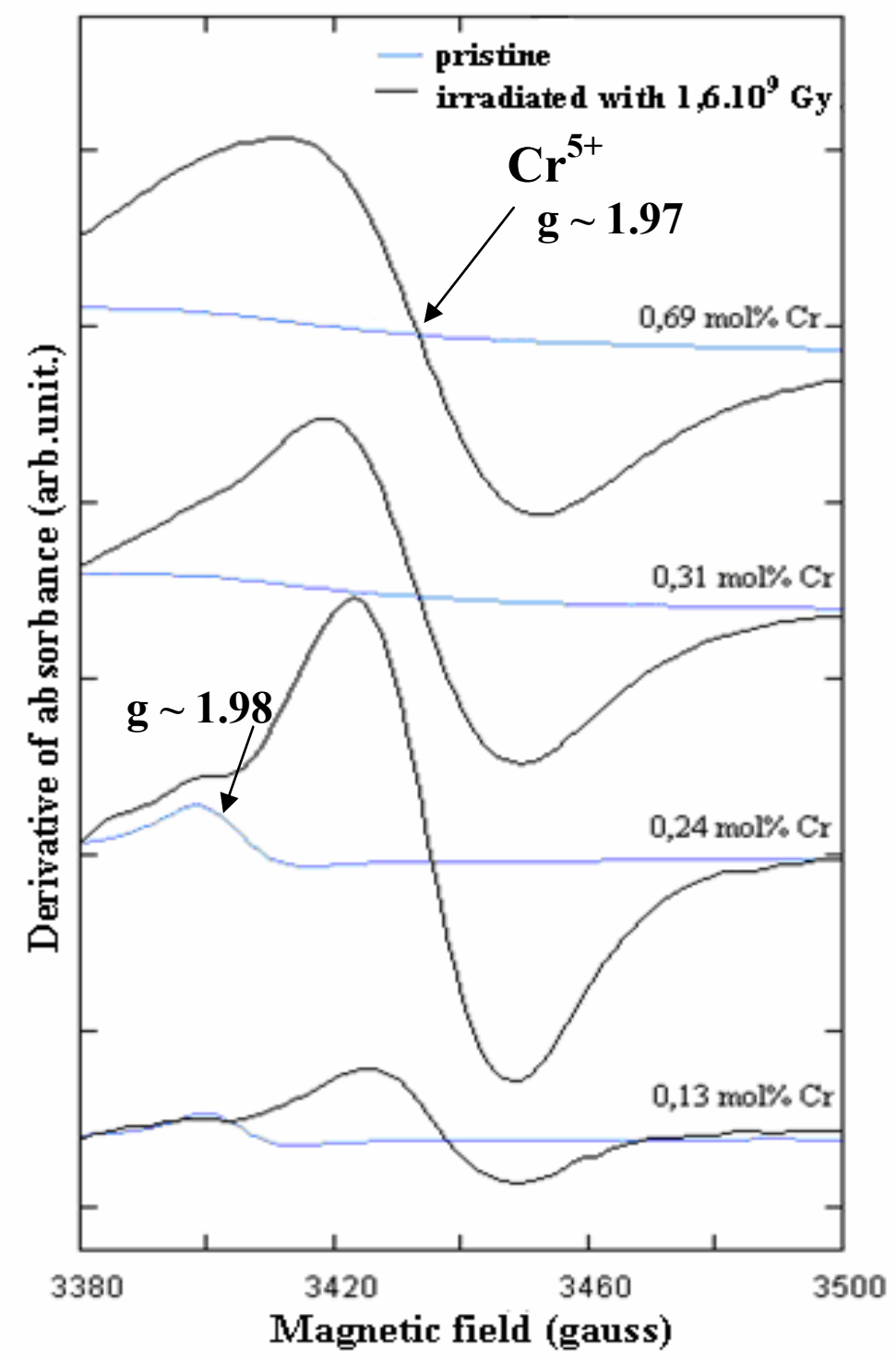

Figure $5 b$. 


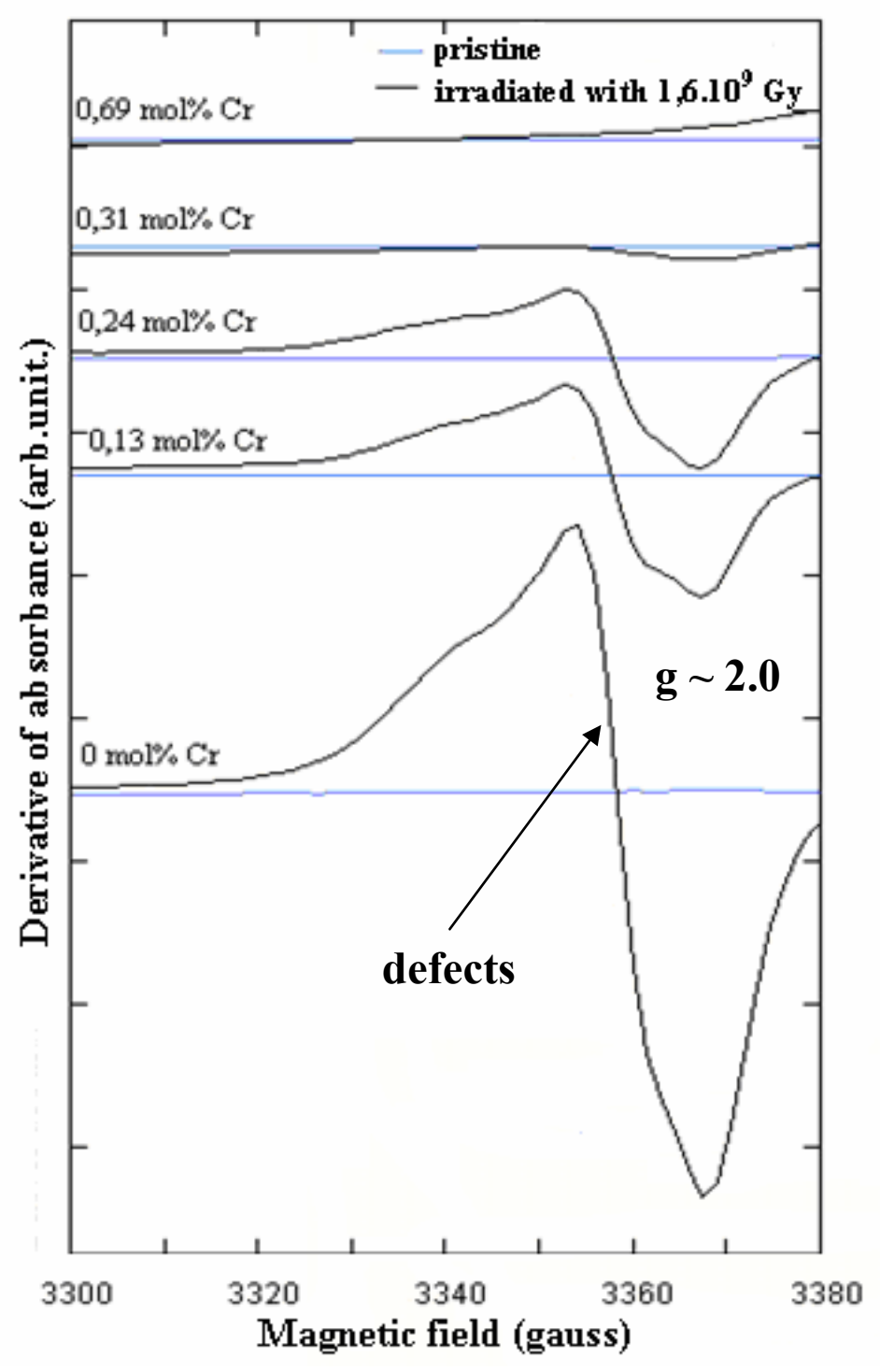

Figure 6. 


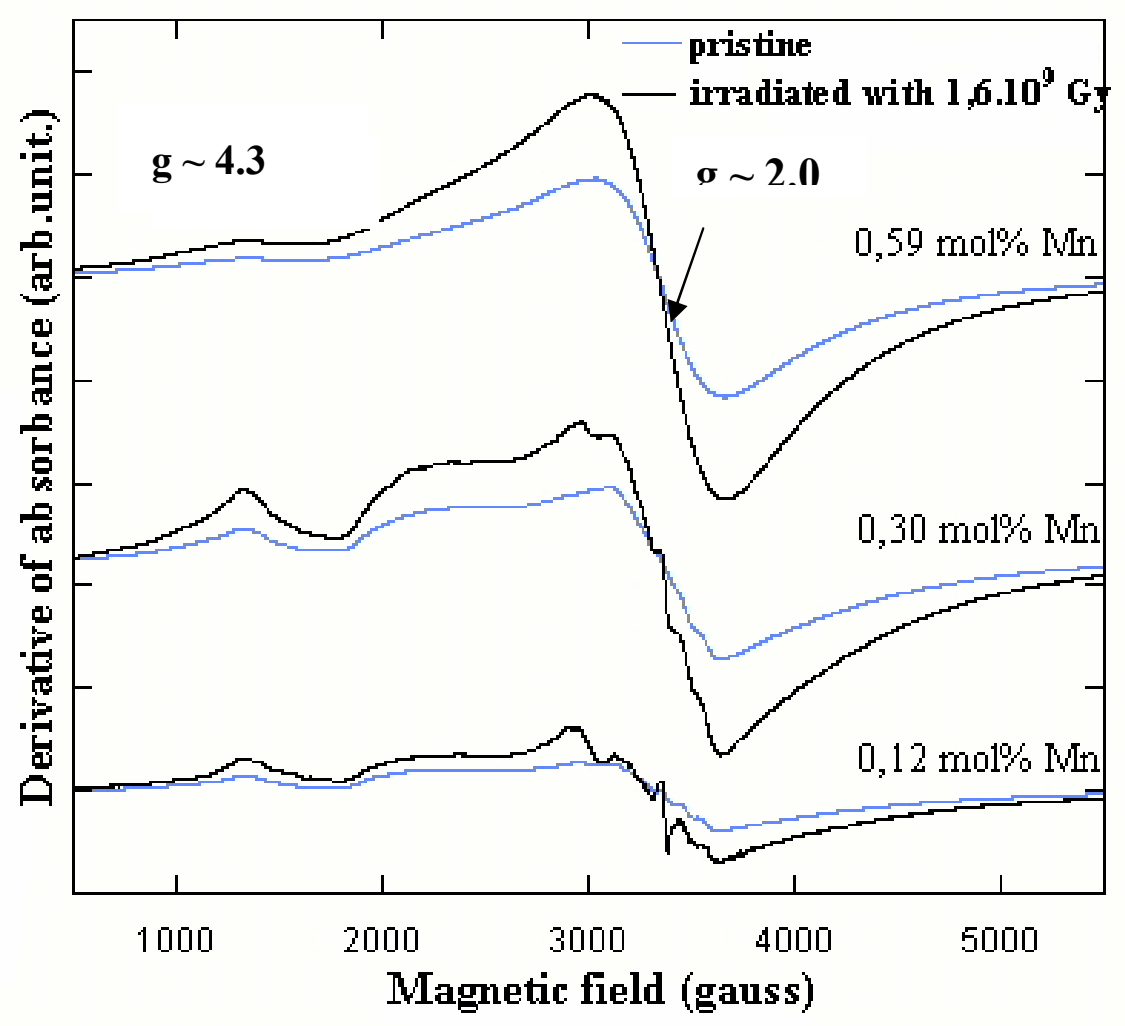

Figure $7 \mathrm{a}$. 


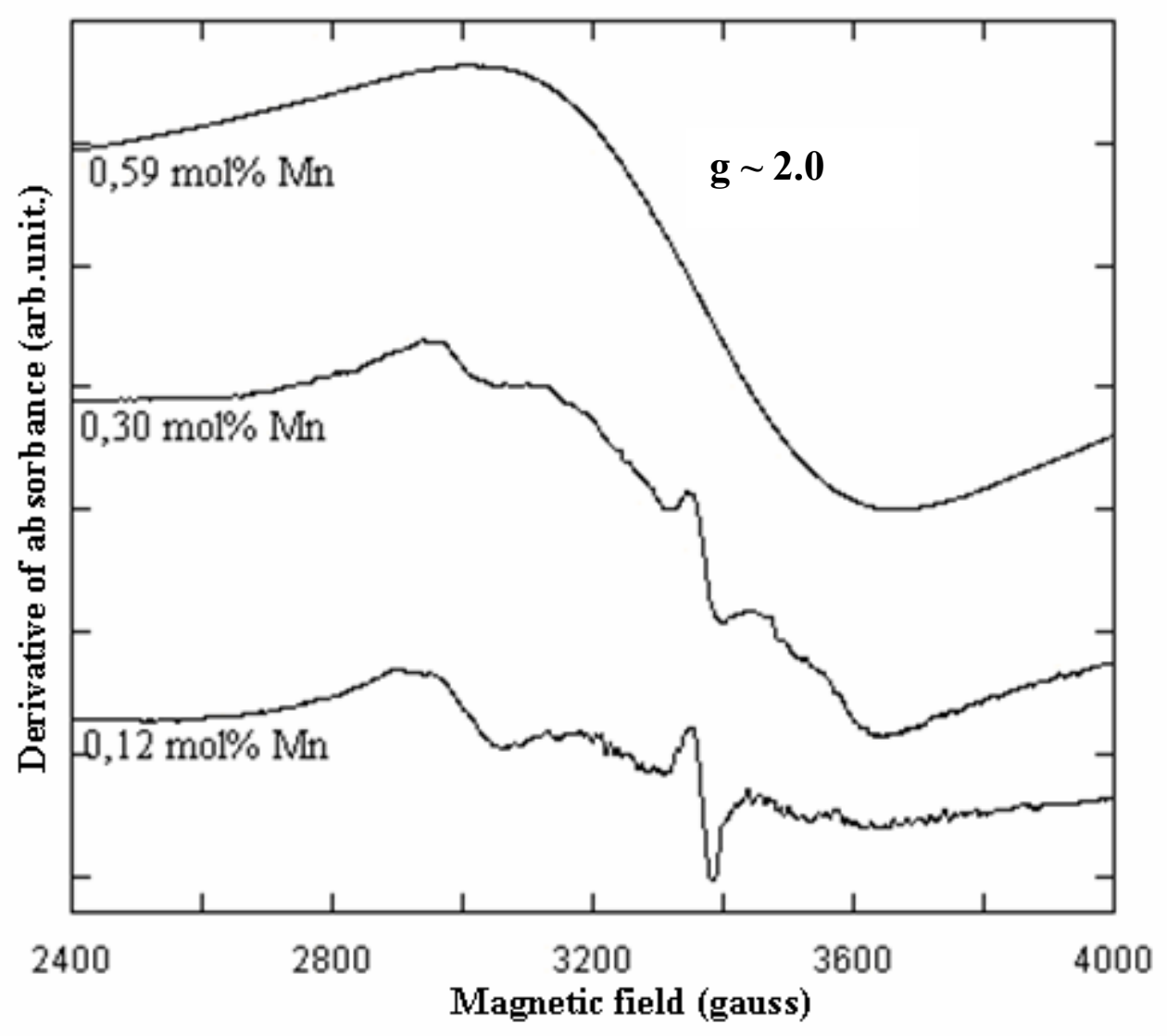

Figure $7 b$. 


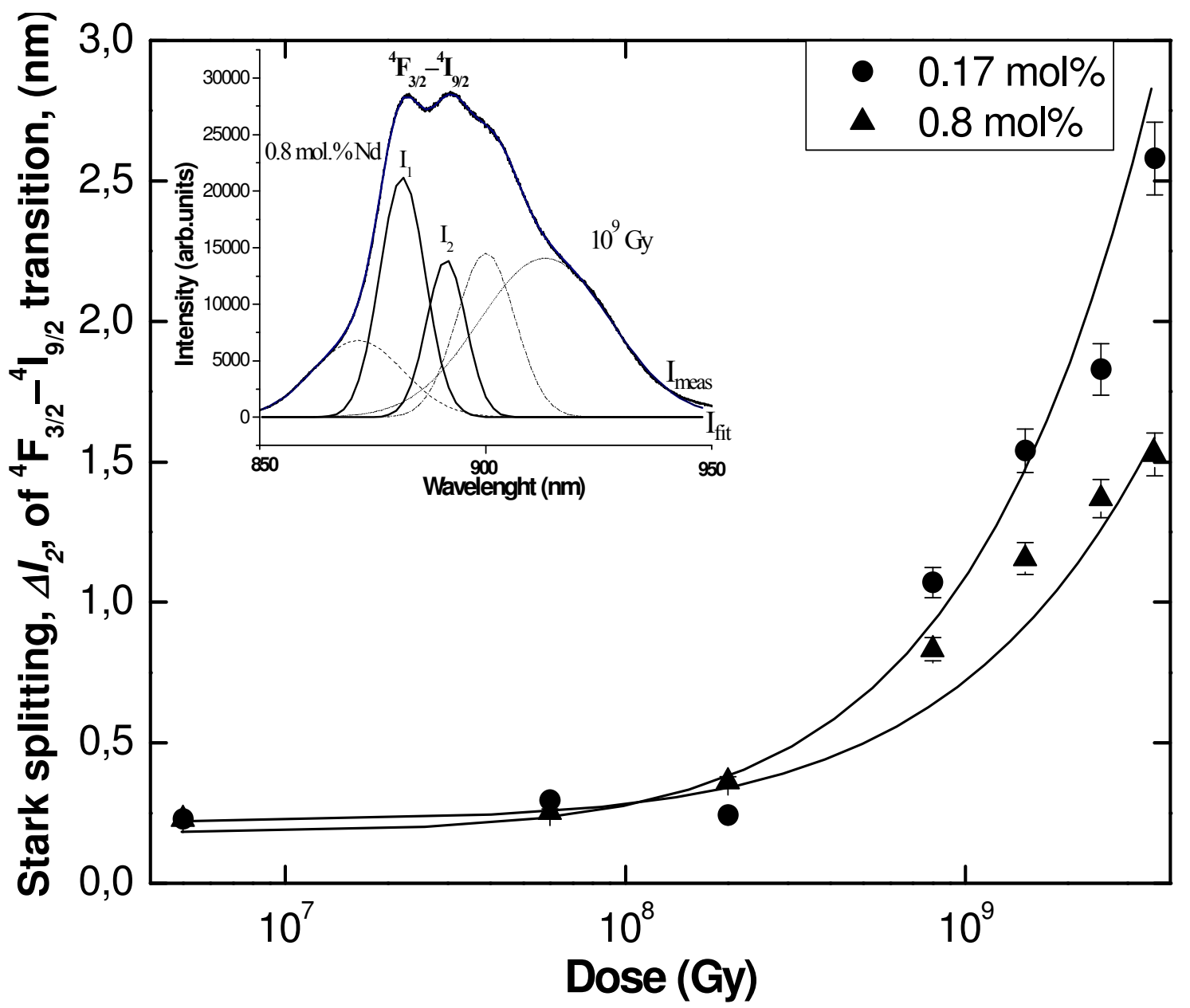

Figure 8. 


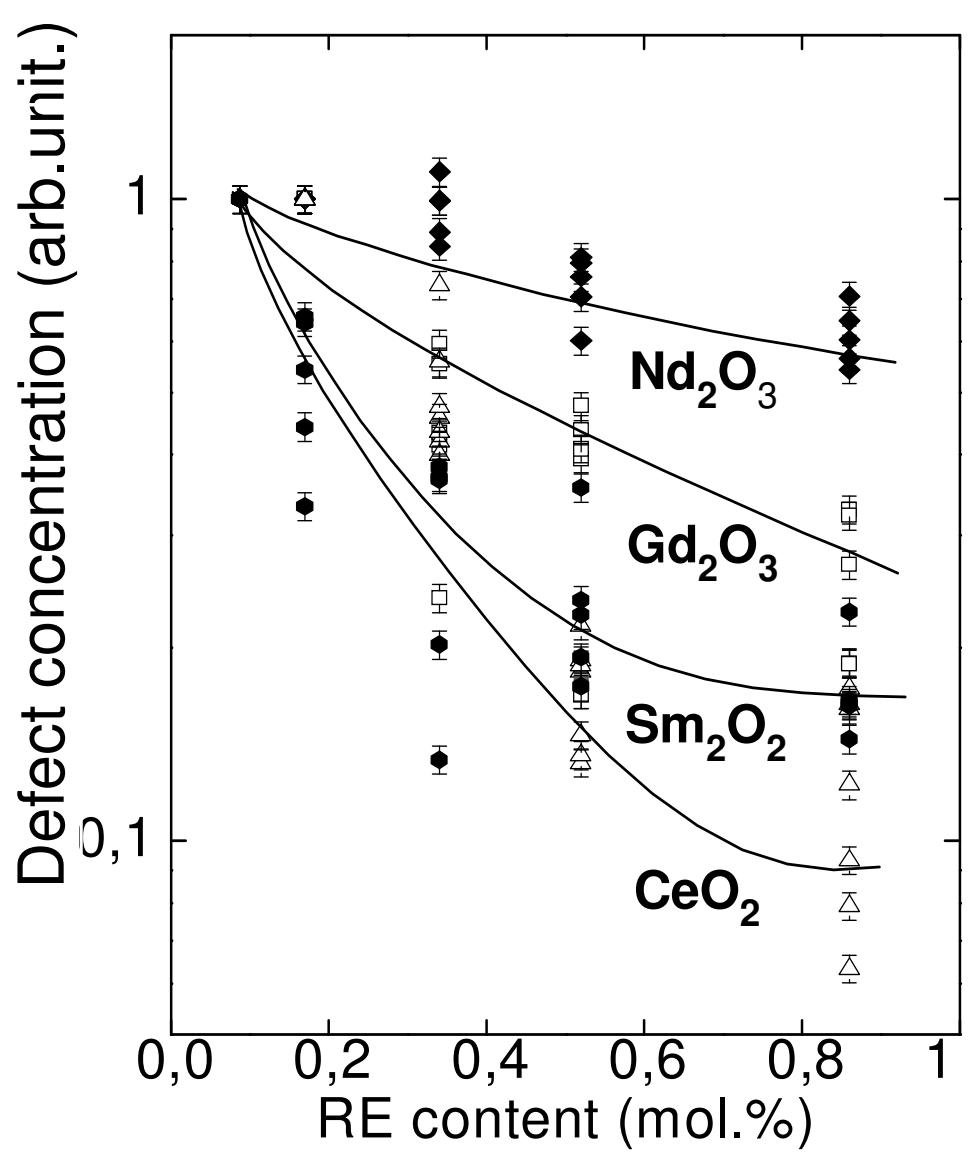

Figure 9. 


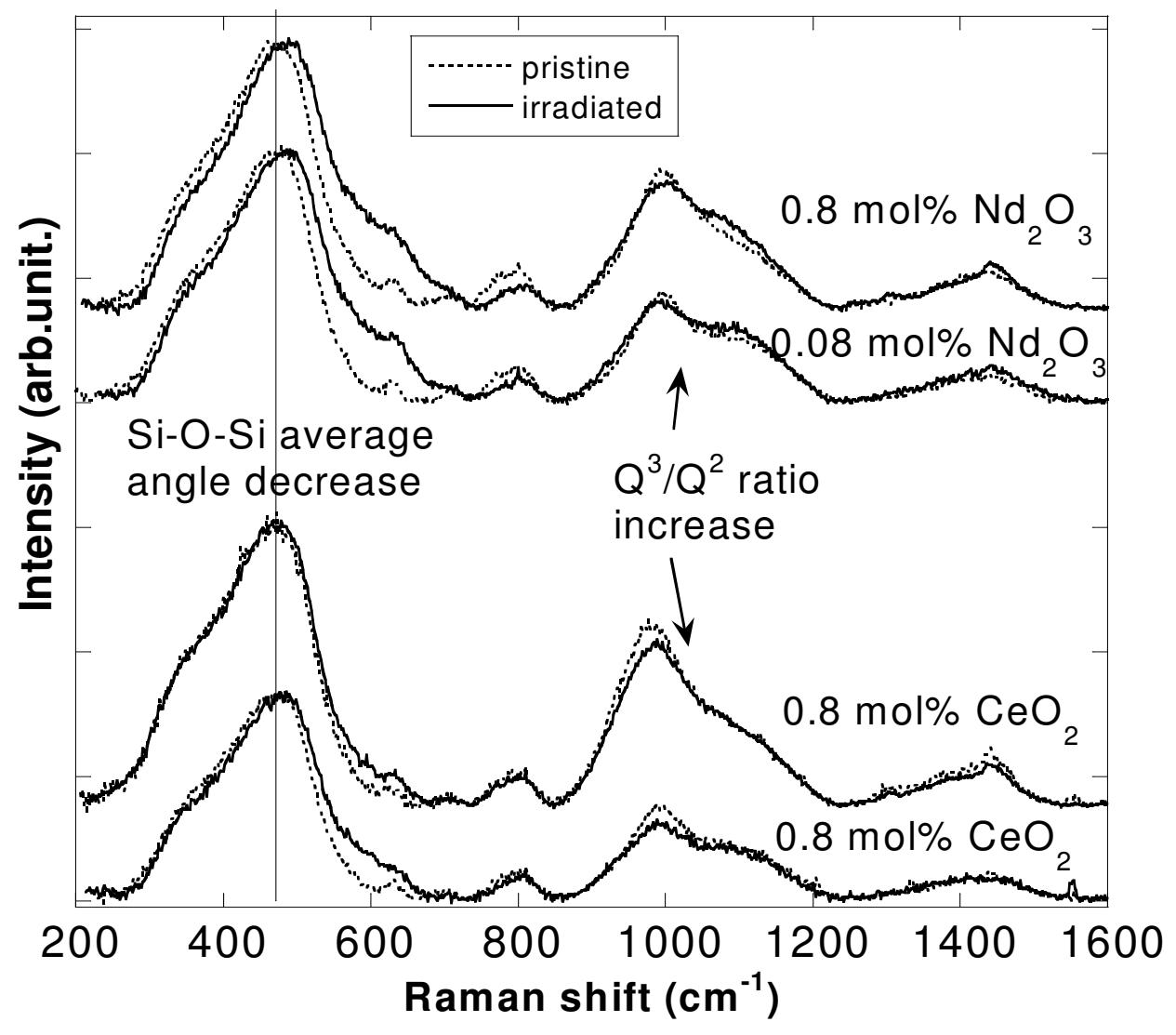

Figure 10a. 


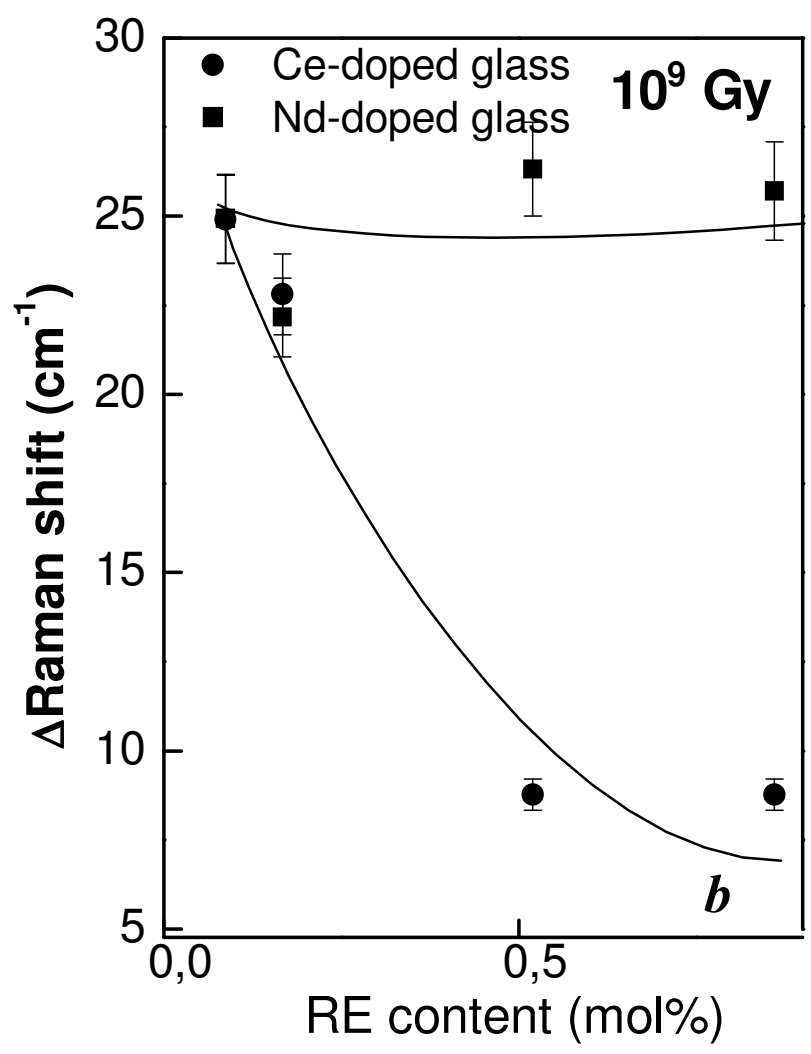

Figure 10b. 


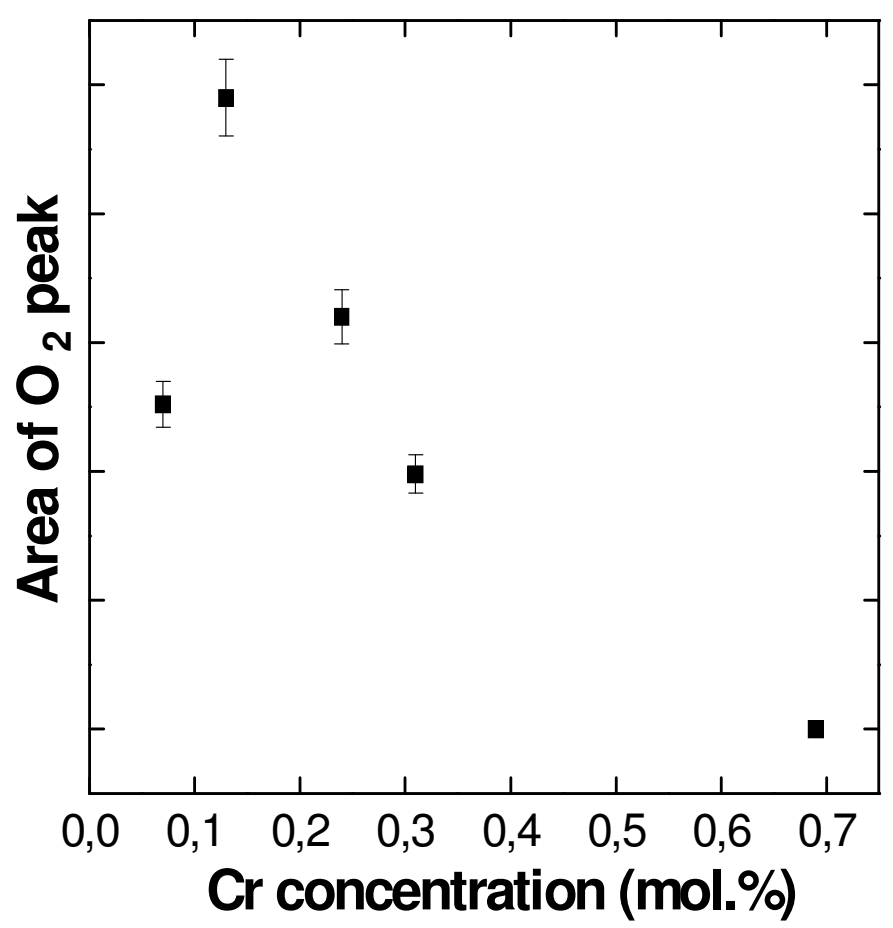

Figure 11 